\title{
Hidrogéis a base de ácido hialurônico e quitosana para engenharia de tecido cartilaginoso
}

\section{Hyaluronic acid and chitosan based hydrogels for cartilage tissue engeneering}

\author{
Mônica Helena Monteiro do Nascimento e Christiane Bertachini Lombello*
}

${ }^{1}$ Human and Natural Sciences Center, Universidade Federal do ABC - UFABC, Santo André, SP, Brazil

Engineering, Modelling and Applied Social Sciences Center, Universidade Federal do ABC - UFABC,

Santo André, SP, Brazil

*christiane.lombello@ufabc.edu.br

\begin{abstract}
Resumo
A Engenharia de Tecidos envolve o desenvolvimento de novos materiais ou dispositivos capazes de interações específicas com os tecidos biológicos, buscando a utilização de materiais biocompatíveis que devem servir como arcabouço para o crescimento de células in vitro, organizando e desenvolvendo o tecido que posteriormente será implantado no paciente. Uma variedade de arcabouços como hidrogéis poliméricos, sintéticos e naturais, têm sido investigados para a expansão de condrócitos in vitro, visando o reparo da cartilagem lesionada. Um hidrogel de interesse particular na regeneração de cartilagem é o ácido hialurónico (AH). Trata-se de um biopolímero atraente para a fabricação de arcabouços artificiais para Engenharia de Tecidos por ser biocompatível e biodegradável. A biocompatibilidade do AH deve-se ao fato de estar presente na matriz extracelular nativa, deste modo, cria-se um ambiente propício que facilita a adesão, proliferação e diferenciação celular, além da existência de sinalização celular específica, o que contribui para a regeneração do tecido. O uso de hidrogel composto de ácido hialurónico e quitosana (QUI) também tem sido investigado em aplicações de Engenharia de Tecidos de cartilagem, com resultados promissores. Baseando-se nestas informações, o objetivo este trabalho foi investigar as alternativas disponíveis para regeneração tecidual da cartilagem e conhecer mais detalhadamente as relações entre células e biomateriais.
\end{abstract}

Palavras-chave: ácido hialurônico, biocompatibilidade, engenharia de tecidos, quitosana, cultura de células.

\section{Abstract}

Tissue Engineering involves the development of new materials or devices capable of specific interactions with biological tissues, searching the use of biocompatible materials as scaffolds for cell growth in vitro, organizing and developing tissue that is subsequently implanted into the patient. A variety of scaffolds such as polymeric hydrogels, natural and synthetic, have been investigated for the expansion of chondrocytes in vitro in order to repair the damaged cartilage. A hydrogel of particular interest in cartilage regeneration is hyaluronic acid (HA). HA are attractive biopolymers for manufacturing artificial scaffolds for Tissue Engineering, it is biocompatible and biodegradable. The biocompatibility of HA is due to the fact that it is present in native extracellular matrix, thus creates an environment, which facilitates the adhesion, proliferation and differentiation, in addition to the existence of specific cell signaling, which contributes to tissue regeneration. The use of hydrogel composed of hyaluronic acid and chitosan (CHI) has also been investigated for applications in Tissue Engineering of soft tissues, like cartilage, with promising results. Based on this information, this study aims to investigate the alternatives available for cartilage tissue regeneration and meet more detail the relationships between cells and biomaterials.

Keywords: hyaluronic acid, biocompatibility, tissue engineering, chitosan, cell culture.

\section{Introdução}

As patologias de tecidos cartilaginosos vêm sendo objeto de estudos relevantes nos últimos anos por representarem um importante problema de saúde mundial. Danos à cartilagem articular continuam sendo uma questão desafiadora na área da ortopedia. A cartilagem articular é conhecida por ter uma pobre capacidade intrínseca para o reparo, devido em grande parte à sua avascularidade e ao acesso limitado às células reparadoras. As células deste tecido apresentam baixo índice mitótico, o que contribui para a sua limitada capacidade de regeneração ${ }^{[1]}$. 
Por esse motivo, pequenos ferimentos na cartilagem articular podem evoluir para danos progressivos e degeneração tecidual. Os tratamentos convencionais, cirúrgicos ou não, podem trazer uma importante melhora da sintomatologia do paciente, no entanto não garantem necessariamente o reparo do tecido lesado. Os resultados mais positivos para a regeneração da cartilagem, principalmente dos tecidos articulares, se referem ao uso de terapia celular ${ }^{[2]}$.

Atualmente, a Engenharia de Tecidos vem despontando como um ramo científico capaz de fornecer metodologias promissoras para o tratamento de patologias do tecido cartilaginoso. Segundo Langer e Vacanti ${ }^{[3]}$, este é um campo científico-tecnológico interdisciplinar que aplica os conceitos de engenharia e ciências da vida com o intuito de desenvolver substitutos biológicos capazes de restaurar, preservar e restabelecer as funções de um órgão ou tecido lesado. Os três elementos constituintes da Engenharia de Tecidos são, fundamentalmente, o arcabouço (scaffold), as células, e o microambiente fisiológico.

Os arcabouços são componentes fundamentais na Engenharia de Tecidos, na medida em que fornecem o suporte estrutural à fixação e crescimento das células, criando um microambiente propício para a substituição ou reparação dos tecidos, e auxiliando estruturalmente o tecido recém-formado ${ }^{[4]}$. Os arcabouços, ao mimetizar a matriz extracelular (MEC), devem interagir com as células de maneira específica e direcionada a fim de obter comportamentos específicos, relacionados à adesão, espalhamento, crescimento e diferenciação celulares.

Uma variedade de arcabouços como hidrogéis, de polímeros sintéticos ou naturais, têm sido investigados para o cultivo de condrócitos in vitro, visando o reparo da cartilagem lesada. Um hidrogel de interesse particular na regeneração de cartilagem é o ácido hialurónico $(\mathrm{AH}) . \mathrm{OAH}$ é um polímero de origem natural, pertencente à família dos glicosaminoglicanos (GAGs), presente em abundância na matriz extracelular da cartilagem articular e desempenha papel importante numa variedade de processos celulares. Trata-se de um hidrogel atraente para a fabricação de arcabouços artificiais para Engenharia de Tecidos por ser biocompatível, biodegradável e apresentar benefícios no tratamento inicial em lesões osteoartríticas ${ }^{[5-7]}$.

Contudo, deve-se utilizar o AH em relativa baixa quantidade, uma vez que a presença em excesso deste biopolímero pode promover a redução da adesão celular devido à carga negativa característica deste GAG. Esta complicação pode ser superada pela combinação entre o AH e hidrogéis de carga positiva (policátions) tais como a quitosana (QUI). Este biomaterial polimérico tem origem natural, apresenta importante biocompatibilidade e biodegradabilidade, além de ser um polissacarídeo com estrutura molecular bastante similar à de GAGs presentes na cartilagem articular ${ }^{[5]}$. Como as GAGs, a QUI está fortemente envolvida na modulação de processos celulares, como a condrogênese, por interagir com fatores de crescimento e citocinas. Além disso, estudos realizados com hidrogéis compostos por AH e QUI reportaram a maior adesão celular nas blendas, demonstrando que a QUI melhorou a bioestabilidade e a biocompatibilidade do $\operatorname{arcabouço~}^{[8]}$.
Tendo em vista a necessidade de aprimorar as alternativas disponíveis para regeneração tecidual da cartilagem e conhecer mais detalhadamente as relações entre células e biomateriais, este estudo traz a revisão de tópicos relacionados à área da Engenharia de Tecidos, especificando a utilização de hidrogéis à base de $\mathrm{AH}$ e QUI como substratos para a cultura de células.

\section{Engenharia de Tecidos}

Quando a estrutura biológica de um órgão ou tecido não pode ser naturalmente reparada, a alternativa viável para o restabelecimento das funções normais do paciente é, muitas vezes, utilizar um implante feito de um biomaterial ${ }^{[9]}$. A regeneração de órgãos e tecidos vivos, ou o reparo da função destes, é o objetivo da Engenharia de Tecidos. Uma abordagem consiste no recrutamento de células do próprio paciente, que são dissociadas dos tecidos originais e cultivadas sobre arcabouços biológicos ou sintéticos, conhecidos como scaffolds (arcabouços, suportes, matrizes tridimensionais, ou estruturas), para então serem reinseridos no paciente.

Como uma ciência multidisciplinar a Engenharia de Tecidos envolve conhecimentos das áreas de biologia, ciências da saúde, engenharia e ciência dos materiais ${ }^{[9]}$. O termo "Engenharia de Tecidos" foi citado pela primeira vez numa reunião patrocinada pela NSF (National Science Fundation) em 1987 e num Workshop a Engenharia de Tecidos foi definida como

Aplicação de princípios e métodos de engenharia e ciências da vida com o propósito do entendimento fundamental das relações estrutura-função nos tecidos normais e patológicos dos mamíferos e o desenvolvimento de substitutos biológicos para recuperar, manter, ou incrementar a função do tecido $^{[10]}$.

No final da década de 80, a Engenharia de Tecidos começou a ser ministrada em centros de ensino com o objetivo de avançar nos conhecimentos e pesquisas no tratamento de doenças utilizando abordagens celulare ${ }^{[11]}$. Durante a década de 1990, a Engenharia de Tecidos progrediu rapidamente com o desenvolvimento de alguns substitutos biológicos de tecidos. Produtos biomédicos como pele artificial, com células viáveis, e terapia celular, com condrócitos autólogos cultivados, entraram prontamente no mercado ${ }^{[2,12,13]}$.

Para criar um tecido substituto, um número pequeno de células, idealmente, pode ser colhido do paciente usando uma técnica de biopsia e as células são então cultivadas para a obtenção de um número apropriado em laboratório. Estas células podem então ser cultivadas em arcabouço (natural ou sintético), na presença de fatores de crescimento. Se providas com as condições e sinalização adequados, as células irão secretar vários componentes da matriz extracelular (MEC) para criar de fato um tecido vivo que pode ser usado como tecido substituto a ser reimplantado no paciente ${ }^{[9,14]}$

A avaliação dos progressos da Engenharia de Tecidos em suas mais diversas aplicações clínicas (pele, osso, cartilagem, nervos, medula óssea, vasos sanguíneos, córnea, 
válvulas cárdicas e miocárdio) é francamente satisfatória. Ao longo de anos têm sido desenvolvidos, disponibilizados e comercializados inúmeros substitutos funcionais e estruturais para aplicação clínica ${ }^{[15]}$.

\subsection{Arcabouços para cultura de células}

A primeira etapa na Engenharia de Tecidos inicia-se com o desenvolvimento, seleção e processamento dos arcabouços. Os biomateriais, utilizados na Engenharia de Tecidos como arcabouços para cultura de células, podem ser definidos como um material não viável, ou seja, não vivo, utilizado em um dispositivo médico com intenção de interagir com sistemas biológicos ${ }^{[16]}$.

Quanto ao tipo de material, estes biomateriais podem ser: polímeros, metais, cerâmicas e compósitos. É desejável que estes arcabouços sejam biocompatíveis, de maneira que apresentem a capacidade de induzir uma resposta apropriada do hospedeiro, minimizando as reações imunológicas; e biodegradáveis, onde os produtos de degradação não devam ser citotóxicos, tumorigênicos, ou causar qualquer outro efeito indesejável ao organismo. Os polímeros compõem uma classe bastante ampla de biomateriais, classificados como naturais (por exemplo: colágeno, agarose, alginato, fibrina, $\mathrm{AH}$, gelatina, gel de plaquetas e glicosaminoglicanos) ou sintéticos (por exemplo: poli( $\alpha$-hidróxi ácidos e poliHEMA) ${ }^{[9,17]}$.

A biocompatibilidade de alguns polímeros naturais, como o colágeno e o $\mathrm{AH}$, deve-se ao fato destes compostos estarem presentes na matriz extracelular nativa. Deste modo, cria-se um ambiente propício que facilita a adesão, proliferação e diferenciação celular, para além da existência de sinalização celular específica, o que contribui para a regeneração do tecido ${ }^{[16]}$.

Em função da permanência no corpo, os biomateriais podem ser classificados como permanentes ou temporários. Os materiais permanentes são utilizados com a finalidade de substituir um tecido lesionado por tempo indeterminado, assim são produzidos de modo a reter as suas características mecânicas e físico-químicas por longos períodos. Já os biomateriais temporários são utilizados em situações onde se necessita de um suporte que preencha apenas temporariamente a região lesada, até que a recomposição tecidual se concretize, ou ainda que direcione o processo regenerativo ${ }^{[18]}$

As propriedades mecânicas e físico-químicas dos arcabouços utilizados na Engenharia de Tecidos são características importantes, que influenciam a sua aplicação final. Estes arcabouços não só apresentam uma função mecânica, como também apoiam a fixação, migração, proliferação e diferenciação celular para expressão de fenótipos desejáveis ${ }^{[16,19]}$.

As propriedades mecânicas dos arcabouços como a resistência à tração, flexão e compressão, ductilidade (propriedade de suportar a deformação sem romper ou fraturar) e módulo de Young (razão entre tensão e deformação no regime elástico) são determinadas tanto pelas propriedades do material quanto pela estrutura do mesmo (macro, micro e nanoestrutura). A combinação das propriedades mecânicas do arcabouço com o ambiente do enxerto é de crucial importância para que a progressão da recuperação tecidual não seja limitada por falhas mecânicas do $\operatorname{arcabouço~}^{[20]}$. Já propriedades químicas como: hidrofillicidade, hidrofobicidade e cargas elétricas superficiais regulam o contato célula-tecido, e devem ser mimetizadas para obtenção de melhores resultados no desenvolvimento tecidual ${ }^{[21]}$.

É importante também salientar que a estrutura química do biomaterial e o seu processamento determinam as propriedades funcionais e a interação das células com o arcabouço $^{[22]}$. Além disso, estes arcabouços podem ser projetados de duas formas: porosos e não porosos ou densos.

A porosidade é uma característica fundamental para que ocorra o alojamento adequado das células, propiciando a interação arcabouço-célula, bem como uma otimização do transporte de nutrientes e de gases através matriz tridimensional, por meio da vascularização deste. Em particular, a microporosidade é importante para ingresso capilar e interações entre células e matriz, enquanto a macroporosidade é relevante para o fornecimento de nutrientes e remoção de resíduos do metabolismo celular. A porosidade não deve ser excessiva, afim de não comprometer a estabilidade mecânica do arcabouço $\mathrm{O}^{[15,21,23,24]}$.

Além do tamanho dos poros, a sua morfologia pode significativamente influenciar o desempenho de uma matriz implantada e a taxa de crescimento interna do tecido. A porosidade ideal é estritamente ligada ao tipo de tecido, e várias arquiteturas de tecidos podem ser associadas com um microambiente diferente. Assim, o biomaterial deve ser moldado em diferentes geometrias, de forma a adequar-se às necessidades dos diferentes tipos de tecidos. Formas de disco ou cubo são usualmente utilizadas na regeneração de tecido ósseo, tubular aplicada na regeneração do tecido nervoso, vascular ou na regeneração da traqueia e achatada na engenharia de pele, cartilagem, intestino e fígado ${ }^{[15]}$.

Estes arcabouços provêm um suporte biomecânico inicial até que as células produzam a MEC adequada. Durante a formação, deposição e organização da nova matriz, o ideal é que o arcabouço seja degradado e metabolizado, deixando que o órgão vital ou tecido seja reestabelecido, mantenha ou melhore sua função tecidual ${ }^{[25]}$.

É importante sincronizar o tempo de degradação/absorção do biomaterial com o tempo de regeneração do tecido, possibilitando a transferência gradativa das funções do biomaterial para o tecido recém-formado, não devendo, contudo, originar produtos de degradação que possam interferir com o tecido em crescimento ou originar um processo inflamatório ${ }^{[15,19]}$. Na escolha do biomaterial, deve-se ter ainda em consideração, que há matrizes cujas características químicas definem a sua suscetibilidade à degradação aquosa ou enzimática ${ }^{[9,15]}$.

Segundo Vert et al. ${ }^{[26]}$ dentro da Engenharia de Tecidos os termos biodegradação, bioabsorção e biorreabsorção apresentam definições distintas: biodegradável é um termo utilizado para macromoléculas ou substâncias poliméricas susceptíveis à degradação por atividade biológica, com a redução das massas molares das macromoléculas que formam as substâncias; biorreabsorvível faz referência a materiais poliméricos e dispositivos sólidos que mostram degradação através da diminuição de tamanho e que são reabsorvidos in vivo (por exemplo materiais que são eliminados dos organismo por processos metabólicos, de secreção ou excreção); e bioabsorvível refere-se a materiais poliméricos 
e dispositivos que podem se dissolver em fluidos corpóreos sem qualquer clivagem das cadeias macromoleculares ou diminuição de massa molecular.

\subsection{Interação entre células e biomateriais}

O estudo das interações entre células e biomateriais na Engenharia de Tecidos é de grande importância para a determinação das propriedades biológicas dos implantes. A diversidade de respostas celulares a diferentes materiais evidencia a capacidade das células de discriminar quimicamente o arcabouço e de aderir ou não à sua superfície ${ }^{[11]}$.

O conceito da biocompatibilidade refere-se à capacidade de um biomaterial, utilizado na concepção de arcabouços, desempenhar a sua função desejada no que diz respeito a uma terapia médica, sem suscitar quaisquer efeitos indesejáveis locais ou sistêmicos para o destinatário ou beneficiário daquela terapia, mas gerando a mais apropriada e benéfica resposta celular ou tecidual, numa situação específica. A chave para compreender este conceito é a determinação de quais mecanismos, químicos, bioquímicos, fisiológicos, físicos ou outros, tornam-se funcionais nas condições altamente específicas associadas com o contato entre os biomateriais e os tecidos do corpo, e quais são as consequências dessas interações ${ }^{[9,27]}$.

Neste sentido pode-se citar quatro aspectos mais importantes com relação às interações entre biomateriais e tecidos ${ }^{[14]}$ :

- Fenômenos físicos-químicos de interface relacionados com os primeiros instantes de contato entre o biomaterial, tecido e ambiente de implantação;

- Resposta do tecido e meio orgânico à presença do material;

- Mudanças ocorridas nos materiais como resultados da ação do meio (tecido, fluidos orgânicos) sobre o material: degradação e corrosão;

- Reação de alguma parte do organismo, não diretamente em contato com o implante.

A biocompatibilidade de um biomaterial está estreitamente relacionada ao comportamento das células em contato com a superfície, especialmente a adesão celular. Quando um implante é instalado em um defeito tecidual ou em um meio de cultura in vitro, inicia-se um processo de adsorção de proteínas em sua superfície. Essa camada de proteínas controla a interação das células do tecido adjacente com a superfície do implante ${ }^{[24,28]}$.

O fenômeno de adsorção de proteínas na superfície de arcabouços é motivado pelo fato de que as proteínas possuem geralmente tanto grupamentos polares quanto apolares, favorecendo uma concentração destas numa interface que separa duas fases com distintas características (como entre uma fase líquida - fluidos corpóreos - e a superfície hidrofóbica de um biomaterial). Uma estratégia para se manipular o processo de adsorção de proteínas na superfície de biomateriais diz respeito ao enxerto de cadeias poliméricas especificamente escolhidas na superfície de materiais para controlar a adsorção ${ }^{[14,28]}$.
Desta maneira, a associação dos arcabouços celulares com moléculas sinalizadoras, incluindo fatores de crescimento, citocinas, e os compostos químicos não-proteícos, é comumente utilizada para promover a regeneração do tecido lesado ${ }^{[29,30]}$. Essas moléculas, ao se ligarem a seus receptores na superfície celular, ativam vias de sinalização que irão induzir a proliferação celular, diferenciação e a síntese de proteínas da matriz extracelular. Algumas destas moléculas podem ser liberadas lentamente através de cápsulas poliméricas e podem estimular o crescimento do tecido danificado. Essas biomoléculas permitem também melhorar e orientar a organização e neovascularização de tecidos lesados ${ }^{[4]}$.

Caso a superfície de um biomaterial não seja biorreconhecida pelas células, haverá imediatamente a sinalização para o desenvolvimento de um processo inflamatório resultando na formação de uma cápsula fibrosa que por sua vez isolará o biomaterial do corpo. Caso ocorra o biorreconhecimento, haverá a possibilidade de interação da superfície com células que poderão proliferar e estimular a regeneração dos tecidos, fixação de implantes e provocar menor grau de inflamação ${ }^{[27]}$.

\subsubsection{Dinâmica celular: adesão, proliferação e migração celular}

Quando se trata de regeneração de órgãos e tecidos, torna-se fundamental o estudo do comportamento e diferenciação celular induzidos pela estrutura, composição e presença de elementos biológicos dos arcabouços, para aperfeiçoar os substratos e avançar em técnicas de cultivo celular, que possam permitir a reprodução dos tecidos e órgãos em toda sua complexidade ${ }^{[9]}$.

A interação celular com o substrato deve ser semelhante ao de condições in vivo. Idealmente as características físico-químicas dos arcabouços devem mimetizar a matriz extracelular e esta, por sua vez tem grande influência sobre a migração, proliferação e diferenciação das células ${ }^{[18,31]}$.

Normalmente, para que ocorra uma boa interação arcabouço-célula é necessário que se estabeleça inicialmente a adesão celular ao substrato. O processo de adesão está relacionado com a adsorção de proteínas adesivas e é direcionado por características do substrato como hidrofilicidade, hidrofobicidade e disposição de cargas elétricas de superfície ${ }^{[17,31]}$. Somente após de aderidas, as células iniciam seu processo de espalhamento, proliferação e produção de matriz extracelular ${ }^{[32]}$.

A matriz extracelular (MEC) animal é formada por vários tipos de moléculas (fibronectina, lamininas, elastina, proteoglicanas, colágenos) as quais associam-se entre si formando redes ou malhas. Estas, por sua vez, constituem estruturas morfofisiológicas bem definidas e conhecidas por lamina basal e tecido conjuntivo. Enquanto a algumas macromoléculas de MEC, como os colágenos, atribui-se função estrutural, a outras, como as GAGs, associa-se hidratação $0^{[33-35]}$

Malhas moleculares representam os ambientes naturais da maioria das células e tecidos de mamíferos. Assim sendo, células devem ser capazes de reconhecer e responder a cada uma das dimensões das malhas: química (tipos moleculares), mecânica (tensão e rigidez) e arquitetônica (forma e estrutura dos arranjos moleculares), além de também responderem à 
hidrodinâmica e à físico-química inerentes à hidratação do meio. Tanto a formação quanto a funcionalidade do tecido resultante estarão, dessa forma, diretamente relacionadas à mecanoquímica da malha molecular onde as células formadoras do tecido em questão se encontram ${ }^{[36,37]}$.

A adesão celular a um biomaterial está relacionada a dois fenômenos diferentes: (1) fase de anexação, que ocorre rapidamente, envolve eventos como ligações físico-químicas entre as células e o material por forças iônicas e forças de van der Walls; (2) fase de adesão, que ocorre posteriormente e envolve diversas moléculas biológicas como proteínas de matriz extracelular, proteínas de membrana celular e do citoesqueleto, que interagem conjuntamente para induzir a transdução do sinal, promovendo a ação de fatores de transcrição e consequentemente regulando a expressão gênica. A adesão celular é mediada por diferentes tipos de proteínas receptoras transmembrana conectadas ao citoesqueleto das células. Os aspectos da dinâmica da adesão celular necessitam de regulação destes receptores de adesão celular, que se encontram na superfície da célula. Este fenômeno é crucial para a união de células individuais em tecidos tridimensionais de animais ${ }^{[38]}$.

Os sítios de adesão entre as células e o substrato são chamados de contatos focais ou placas de adesão, sendo a distância de união entre ambos em torno de 10-20 nm. As faces externas dos contatos focais apresentam proteínas receptoras específicas como as integrinas. $\mathrm{Na}$ face interna, proteínas como as talinas, paxilinas, vinculinas e tensinas são conhecidas por mediarem as interações entre filamentos de actina e integrinas. A formação de contatos focais geralmente ocorre em células com baixa motilidade e pode ser produzida in vitro através de proteínas da matriz extracelular como as fibronectinas ou vitronectinas ${ }^{[39]}$.

As comunicações intercelulares podem ocorrer através da troca direta de íons via "gap junctions", também denominadas de junções comunicantes, ou através de sinais produzidos pela ação das caderinas. Junções aderentes e desmossomos promovem uma ancoragem entre as células vizinhas. Já a adesão entre célula e substrato é realizada, preferencialmente, pela família das integrinas, que é composta por 22 heterodímeros de 2 tipos de sub-unidades e, ligadas não covalentemente entre si. Essa diversidade de estruturas ocorre devido às várias possibilidades de ligantes (colágeno, laminina, fibronectina, osteopontina, vitronectina, sialoproteína, trombospondina $)^{[38]}$.

A migração celular requer uma integração entre célula, substrato e citoesqueleto. Primeiramente, as células desenvolvem uma protrusão formando o lamelipódio e, em seguida, utilizam as interações adesivas para gerar tração e energia para o movimento. Por último, ocorre a liberação dos pontos de adesões, seguida pelo destacamento e retração. As integrinas são envolvidas nessa migração celular ${ }^{[38]}$.

Mudanças nas formas dos tecidos, por exemplo, durante o desenvolvimento ou remodelação, frequentemente envolvem migrações celulares extensivas. As células podem migrar individualmente ou como uma parte aderente do tecido, acompanhando mudanças morfogenéticas nos tecidos. Para que a migração celular seja entendida como um processo integrado há a necessidade de pesquisas das propriedades físicas e químicas dos componentes celulares que trabalham juntos como um sistema dinâmico, incluindo sua termodinâmica, cinética e características mecânicas, pois a migração é um processo coordenado tanto espacialmente quanto temporalmente ${ }^{[40]}$.

$\mathrm{Na}$ Engenharia de Tecidos, a migração celular se torna crucial quando se trata de colonização dos arcabouços. Lo et al., (2000) mostraram em seus trabalhos que as células apresentam diferentes morfologias e taxas de motilidade de acordo com a rigidez, flexibilidade e deformação mecânicas do substrato ${ }^{[41]}$

\subsection{Hidrogéis}

Devido à capacidade de simular a natureza da maioria dos tecidos moles, os hidrogéis são biomateriais altamente atraentes para o desenvolvimento de análogos sintéticos da MEC. Essas estruturas de cadeias poliméricas reticuladas possuem alto teor de água e fácil transporte de oxigênio, nutrientes e resíduos. Além disso, muitos hidrogéis podem ser facilmente modificados para apresentar ligantes de adesão celular, viscoelasticidade e degradabilidade ${ }^{[34]}$.

Os hidrogéis são materiais poliméricos que podem ser usados como biomateriais, pois apresentam uma estrutura tridimensional e importante capacidade de intumescimento em água ou fluidos biológicos, que permitem a inoculação celular sobre estes arcabouços. A massa de água contida em um hidrogel após intumescimento pode variar de 10 a milhares de vezes de sua massa inicial ${ }^{[42]}$

Para que possam ser utilizados como arcabouços, os hidrogéis poliméricos devem sofrer processo de reticulação. Este processo pode ser realizado por métodos químicos, envolvendo ligações covalentes entre cadeias poliméricas, ou métodos físicos, como interações iônicas e interações por cristalização, que envolvem forças e interações intermoleculares ${ }^{[9,42,43]}$. Para a preservação estrutural do hidrogel no seu estado hidratado é necessário a formação de ligações intermoleculares que resultem no balanço entre o padrão de densidade de reticulação e capacidade de intumescimento ${ }^{[42]}$. Alguns protocolos de reticulação têm sido utilizados com êxito, permitindo que hidrogéis poliméricos sejam aplicados em Engenharia de Tecidos, e garantindo as suas propriedades de biocompatibilidade, biodegradação e bioatividade $^{[44]}$. Estes retículos são formados por ligações intermoleculares de modo que evitam a dissolução das cadeias poliméricas e contêm domínios ou grupos hidrofílicos que são hidratados em meio aquoso para formar a estrutura tridimensional do hidrogel ${ }^{[43]}$.

Os hidrogéis podem ser classificados de diversos modos. Quanto ao método de formação das cadeias, os hidrogéis podem ser classificados em homopolímeros, quando são utilizados apenas um tipo de monômero; copolímeros, quando são utilizados mais de um tipo de monômero; polímeros interpenetrantes, quando as cadeias poliméricas de um dado hidrogel penetram e se emaranham com as cadeias de um outro hidrogel, formando blendas de hidrogéis. Quanto à carga iônica, os hidrogéis podem ser classificados em neutros, quando os meros do hidrogel não apresentam grupamentos ionizávei, poli(metil metacrilato), por exemplo; catiônicos, quando os meros do hidrogel apresentam grupamentos capazes de formação de cátions por variação do $\mathrm{pH}$ do meio reacional; e aniônicos, quando os meros do hidrogel 
apresentam grupamentos capazes de formação de ânions por variação do $\mathrm{pH}$ do meio reacional ${ }^{[45]}$.

A capacidade dos hidrogéis de se ligar com moléculas de água surge principalmente devido à presença de grupos hidrofílicos tais como grupos aminos, carboxilas e hidroxilas. Esta propriedade dos hidrogéis é denominada grau de intumescimento que é diretamente proporcional à quantidade de água absorvida pelo hidrogel ${ }^{[42]}$.

Os hidrogéis utilizados para a cultura de células podem ser formados a partir de uma vasta gama de materiais naturais e sintéticos, oferecendo um amplo espectro de propriedades mecânicas e químicas. Hidrogéis naturais para a cultura de células são tipicamente formados de proteínas e componentes da matriz extracelular, como colágeno, fibrina, $\mathrm{AH}$, bem como de materiais de outras fontes biológica, tais como QUI, alginato ou de fibrilas de seda. Uma vez que são derivados de fontes naturais, estes hidrogéis são inerentemente biocompatíveis e bioativos ${ }^{[46]}$. Eles também promovem muitas funções celulares, devido a presença de fatores endógenos, o que pode ser vantajoso para a viabilidade, proliferação e desenvolvimento de muitos tipos de células ${ }^{[34]}$. Por outro lado, os hidrogéis podem ser formados por moléculas sintéticas, tais como poli (etileno glicol) (PEG), poli (álcool vinílico) e poli (2-hidroxi-etil-metacrilato) $^{[34]}$.

\subsection{1 Ácido hialurônico}

O AH é um hidrogel atraente para a fabricação de arcabouços artificiais para engenharia tecido porque é biocompatível, biodegradável, bioativo, não-imunogénico e não-trombogênico ${ }^{[7]}$. Trata-se de um polissacarídeo linear de alta massa molar pertencente à família dos GAGs e é composto por unidades dissacarídicas polianiônicas de ácido D-glicurônico (GlcUA) e N-acetilglicosamina (GlcNAc) unidas alternadamente por ligações $\beta(1 \rightarrow 3)$ e $\beta(1 \rightarrow 4)^{[47]}$.

$\mathrm{O}$ AH produzido comercialmente é obtido de materiais ou estruturas de origem animal e/ou de bactérias, através do isolamento direto ou da fermentação. $\mathrm{O} \mathrm{AH}$ está presente em todos os vertebrados e também na cápsula de algumas cepas de Streptococcus sp., mas está ausente em fungos, plantas e insetos ${ }^{[48]}$. O AH é encontrado principalmente na matriz do tecido conjuntivo e é produzido por células de origem mesenquimal, com função de organizar os elementos da matriz extracelular (MEC $)^{[49]}$. O AH é sintetizado por três tipos de enzimas sintases (AHS1, AHS2 e AHS3) que estão localizadas na membrana celular, e é imediatamente secretado para a MEC onde interage com os demais constituintes para fornecer suporte mecânico ao tecido ${ }^{[50]}$.

No ser humano, este mucopolissacarídeo está presente no líquido sinovial, na pele, nos tendões, no humor vítreo e no cordão umbilical. Na pele, bem como nas cartilagens, a função do AH é ligar-se à água, mantendo a tonicidade e a elasticidade desses tecidos. No líquido sinovial, sua função básica é o de manter um suporte protetivo e lubrificante para as células das articulações. No olho, atua como componente natural dos tecidos oculares, tais como córnea, esclera e corpo vítreo ${ }^{[44,51]}$.

Em condições fisiológicas, o AH apresenta abundantes cargas negativas (devido a presença de radicais carboxila e $\mathrm{N}$-acetila), podendo assim absorver grandes quantidades de água, formando uma estrutura hidratada em forma de rede, controlando o transporte de água e restringindo o movimento de agentes patogênicos, proteínas plasmáticas, e proteases ${ }^{[50]}$.

O AH é também um composto reconhecido por sua importância em controlar e regular o comportamento das células e a interação célula-célula, especialmente no decurso do reparo de tecidos. Este último inclui a ativação e modulação das respostas imunes, promoção de angiogênese, bem como a proliferação e migração celular ${ }^{[52]}$.

Desta maneira, o AH interage com receptores de superfície celular, por exemplo: CD44, ICAM-1 e RHAMM, para ativar várias vias de sinalização, tais como c-Src, Ras e proteínas quinase ativadas por mitógenos (MAPK). Estas vias regulam várias funções celulares, incluindo a adesão celular, rearranjo do citoesqueleto, migração, proliferação e diferenciação ${ }^{[52,53]}$. Especificamente, os receptores RHAMM e CD44 têm sido sugeridos como os principais fatores envolvidos na motilidade celular. Ambos os receptores de AH são bem conhecidos por estarem envolvidos no reparo de feridas e tem sido demonstrado em numerosos estudos que a regulação da motilidade celular, contribui para uma variedade de doenças, incluindo artrite e câncer ${ }^{[54]}$.

$\mathrm{O} \mathrm{AH}$ pode ser rapidamente degradado na MEC por espécies de oxigênio reativas ou pelas enzimas hialuronidases, e o tempo de meia-vida in vivo pode variar de horas a dias, dependendo do tipo de tecido ${ }^{[53]}$.

Devido a sua biocompatibilidade, o $\mathrm{AH}$ vem sendo utilizado como biomaterial em diversas aplicações, as quais são divididas em cinco grandes grupos: viscocirurgia - para proteger tecidos delicados e fornecer espaço durante as manipulações cirúrgicas ou em cirurgias oftalmológicas; "viscoaugmentation" ou aumento de volume - para preencher e aumentar os espaços nos tecidos, como na pele, nos músculos esfíncter, nos tecidos vocais e na faringe; viscosseparação para separar a superfície de tecidos conectivos traumatizados por processos cirúrgicos ou lesões, a fim de evitar adesões e formação excessiva de cicatrizes; viscossuplementação - para substituir ou suplementar fluidos de tecidos, como a substituição do fluido sinovial em artrites dolorosas, e para aliviar a dor; viscoproteção - para proteger superfícies de tecidos saudáveis, feridos ou lesionados, de securas ou agentes nocivos do ambiente, e para promover a cicatrização dessas superfícies ${ }^{[55]}$.

Na medicina clínica o AH é usado como um marcador diagnóstico para várias doenças, como câncer, artrite reumatóide, patologias hepáticas e suplementação de fluido sinovial debilitado em pacientes com artrite. O AH também é usado em certas cirurgias oftalmológicas, na reconstrução de tecidos moles e em revestimentos hidrofílicos para dispositivos médicos. Além disso, o AH é utilizado em cosméticos devido à sua alta capacidade de retenção de água e em sistemas de liberação modificada de fármacos, devido à sua biodegradabilidade ${ }^{[4,48,56]}$.

\subsubsection{Quitosana}

A quitina é um polissacarídeo nitrogenado composto por ligações $\beta(14) 2$ acetamino-2-desoxi- $\beta$-D-glicose, geralmente derivada do exoesqueleto de animais marinhos, tais como caranguejo, camarão, lagosta e krill. Estima-se que 2,3 milhões de toneladas de quitina são produzidas como 
resíduos da indústria de alimentos a cada ano tornando-se um material econômico e renovável. No entanto, a quitina é considerada quimicamente inerte e é insolúvel em água e solventes orgânicos. AN-desacetilação da quitina conduz ao seu principal derivado, a QUI. O grau de desacetilação é um fator importante para a determinação das características da QUI ${ }^{[57]}$.

A QUI é um polissacarídeo natural, estruturalmente similar às GAGs, atóxica e bioabsorvíve ${ }^{[2]}$. Devido à sua biocompatibilidade e biodegradabilidade, a QUI tem sido amplamente aplicada na entrega de drogas, terapia gênica, tratamento de águas, produção de cosméticos, aditivos alimentícios, membranas semipermeáveis e no desenvolvimento de biomateriais para a Engenharia de Tecidos ${ }^{[58,59]}$.

Como citado anteriormente, este biomaterial polimérico é comumente obtido por desacetilação de quitina, e seus meros permanecem unidos por ligações $\beta(14)$. A presença de grupamentos amina na composição da QUI é responsável por sua natureza policatiônica em soluções ácidas. Sua natureza catiônica é responsável pelas interações eletrostáticas com GAGs, proteoglicanos e demais moléculas carregadas negativamente, tanto presentes na matriz extracelular, quanto na superfície celular ${ }^{[57]}$.

Como um polímero natural, a QUI possui propriedades favoráveis em aplicações na Engenharia de Tecidos. Foi demonstrado que este tipo de substrato é capaz de interagir com células vivas, sem apresentar sinais de citotoxicidade ou desencadear uma resposta imunitária,

$\mathrm{O}$ estudo realizado por Nwe et al. ${ }^{[60]}$, mostrou que o número de células aderidas no arcabouço de QUI foi altamente dependente do grau de desacetilação e o tipo da linhagem celular utilizada. Menor grau de desacetilação favorece a formação de poros menores, desta forma é possível obter uma melhor resistência mecânica, absorção moderada de água e maior atividade celular comparado com arcabouços produzidos com altos graus de desacetilação ${ }^{[60]}$. A importância da desacetilação se dá por conta da limitada solubilidade da quitina $^{[61]}$, o preparo de filmes desse material se da melhor na forma de QUI que é solúvel em soluções aquosas de vários ácidos (ácido acético e clorídrico são as mais utilizadas).

A QUI também apresenta a característica de biodegradabilidade. Quitinases, quitosanases e lisozimas em geral, degradam a QUI em oligômeros e monômeros de QUI e, finalmente, em um amino-açúcar comum, $\mathrm{N}$ - acetilglucosamina que, em seguida, entra no ciclo de glicoproteína e, eventualmente, é excretada na forma de dióxido de carbono. A taxa de degradação de QUI está relacionada com o peso molecular e grau de desacetilação ${ }^{[57]}$.

\subsubsection{Aplicação de hidrogéis a base de ácido hialurônico e quitosana na Engenharia de Tecido de cartilagem}

O tecido cartilaginoso é um tipo especializado de tecido conjuntivo de consistência semi-rigida, avascular, sem inervação, contendo muita MEC esparsamente povoada por células (condrócitos). A matriz cartilaginosa é constituída por colágeno, ou colágeno mais elastina, em associação com macromoléculas de proteoglicanos, $\mathrm{AH}$ e diversas glicoproteínas. Os condrócitos presentes no tecido são altamente especializados e sua principal função é conferir as propriedades biomecânicas ao tecido, pela síntese dos componentes da matriz extracelular ${ }^{[33]}$. Existem várias metodologias sendo empregadas na tentativa de reparar lesões focais da cartilagem articular. Tais metodologias incluem tratamentos cirúrgicos que vão desde métodos de estimulação da medula óssea como desbridamento, perfurações múltiplas, abrasões, microfaturas, até métodos biológicos modernos como transplantes periosteais e pericondrais, transplante autólogo de condrócitos e enxertos autólogos osteocondrais ${ }^{[2]}$. Vários destes métodos biológicos encontram-se associados à Engenharia de Tecidos ${ }^{[62-64]}$. Como in vivo, os tecidos projetados in vitro devem fornecer transporte de nutrientes, estabilidade mecânica, coordenação de processos multicelulares e um microambiente celular que preserve a estabilidade fenotípica das células ${ }^{[65]}$.

Dentre os hidrogéis aplicáveis à engenharia de tecido cartilaginoso, o AH é um GAGs presente na matriz extracelular do tecido cartilaginoso, que fornece um microambiente capaz de manter a homeostase e preservar o estado diferenciado dos tecidos. O AH é uma das moléculas presentes no mesênquima cujo papel é um dos mais fundamentais nas primeiras fases da condrogênese. Além disso, o AH é capaz de influenciar condrócitos a desencadear uma sofisticada sinalização de uma rota metabólica que melhorar as suas funções celulares ${ }^{[5]}$.

Interações celulares entre condrócitos e o AH ajudam a organizar a MEC da cartilagem e manter as proteoglicanas no interior da cartilagem. O AH também estimula a diferenciação condrogênica de células-tronco mesenquimais e a produção de proteoglicanas através da sua interação com os condrócitos ${ }^{[53]}$.

Estudos demonstraram que os condrócitos cultivados em um suporte de $\mathrm{AH}$ expressam colágeno tipo II e agregan e regulam negativamente a produção de colágeno tipo I. Mais recentemente, foi também demonstrado que o AH cria um ambiente em que os condrócitos regulam negativamente a expressão de fatores catabólicos e da apoptose. Estes resultados demonstraram uma capacidade potencial do $\mathrm{AH}$ em prevenir a cartilagem contra danos, além da possibilidade de ter benefícios no tratamento inicial em lesões osteoartríticas ${ }^{[6]}$.

O uso de hidrogel composto de AH e QUI também tem sido investigado em aplicações de Engenharia de Tecidos de cartilagem, com resultados promissores. A natureza catiônica da QUI em meio aquoso ácido é a principal responsável pelas interações eletrostáticas com GAGs aniônicos, proteoglicanos e outras moléculas carregadas negativamente. Esta propriedade é de grande interesse, visto que um grande número de citocinas/fatores de crescimento está ligado aos GAGs (por exemplo, o AH). Um arcabouço incorporando um complexo de quitosana-glicosaminaglicana pode reter e concentrar fatores secretados através da colonização de células $^{[66]}$.

A associação de AH e QUI geralmente leva à formação de um complexo de polieletrólito (PEC) ${ }^{[67]}$. PECs são preparados geralmente através da mistura de dois polímeros de cargas opostas, o que leva a auto-montagem devido ao aumento de entropia ${ }^{[68]}$. Porém, estes hidrogéis compostos não possuem as propriedades de homogeneidade, transparência e estabilidade a curto prazo, que são necessárias no caso de uma formulação injetável. Assim, sistemas mais complexos 
têm sido propostos para contornar estas limitações, nos quais AH e QUI são ligados através de uma reticulação química com agentes tais como carbodiimida, o glutaraldeído, genipina, e di-hidrazida adica ${ }^{[68,69]}$.

Porém, muitas vezes o uso de agentes de reticulação química tem sido vistos como um obstáculo no preparo de hidrogéis, devido à sua toxicidade para células ${ }^{[70,71]}$. Uma alternativa para a associação de AH e QUI, sem a adição de um agente reticulante, é por meio de uma oxidação. Neste caso, o AH é oxidado, usando o periodato, para formar dialdeído (HDA) ou ácido hialurônico oxidado (A-AH). O HDA é posteriormente associado à quitosana por meios de reações de base de Schiff entre os grupos amino da quitosana e grupos aldeído no HDA. Estas modificações químicas, portanto, oferecem a vantagem da formação do gel e do arcabouço sem o uso de agentes de reticulação, podendo assim criar um microambiente com biocompatibilidade melhorada para a regeneração de tecidos ${ }^{[69,72]}$.

O estudo de Muzzarelli et al., (2012) [73] demonstrou que esta blenda de AH e QUI é propícia para propagação e desenvolvimento de condrócitos que, localizados no interior do arcabouço, se re-diferenciaram e sintetizaram cartilagem do tipo hialina. A produção de matriz extracelular também é influenciada pelo arcabouço ${ }^{[5,73]}$. Estudos comparativos demonstram que a adesão e proliferação celulares são mais expressivos quando as blendas são utilizadas como arcabouços, se comparados aos polímeros não associados, $\mathrm{AH}$ e QUI ${ }^{[74]}$

Uma das vantagens do uso de blenda é a possibilidade de utilização clínica na forma injetável, para cirurgias minimamente invasivas. O estudo de Walker e Madihally ${ }^{[75]}$ demonstraram que a incorporação de AH à hidrogéis à base de QUI melhorou a integridade estrutural do hidrogel injetável em relação a outras formulações. O hidrogel injetável, desenvolvido no trabalho de Tan et al. ${ }^{[69]}$, conseguiu preservar o fenótipo de condrócitos e permitiu a adesão dessas células. Yan et al. ${ }^{[8]}$ também reportaram a maior adesão de condrócitos nas blendas, mostrando que a QUI melhorou a bioestabilidade e a biocompatibilidade do biomaterial.

Outra estratégia promissora para a regeneração do tecido cartilaginoso tem sido a combinação da Engenharia de Tecidos com sistemas de entrega de genes terapêuticos. Lu et al. ${ }^{[76]}$ desenvolveram e avaliaram um arcabouço a base de QUI embutidos com nanopartículas de AH/QUI/pDNA (plasmídeo de DNA) que codificam o gene do fator de transformação de crescimento $\beta 1$ (TGF- $\beta 1$ ). O TGF- $\beta 1$ é conhecido por promover a proliferação e diferenciação de condrócitos e consequentemente aumentar a síntese de componentes da $\mathrm{MEC}^{[29]}$. Os condrócitos cultivados neste arcabouço mostraram alta proliferação e aumento da expressão de TGF- $\beta 1^{[76]}$.

\section{Conclusão}

Arcabouços derivados de polissacarídeos naturais são promissores em aplicações de Engenharia de Tecidos, em que se assemelham aos glicosaminoglicanos da matriz extracelular. Nos tecidos, a MEC possui função mecânica e sinalizadora de diferentes comportamentos celulares. Os arcabouços ao mimetizar a MEC, devem interagir com as células de maneira específica e direcionada a fim de obter comportamentos específicos, relacionados à adesão, espalhamento, crescimento e diferenciação celulares. O desenvolvimento de arcabouços a base de hidrogéis poliméricos é objeto de vários estudos, uma vez que estes biomateriais apresentam propriedades cruciais para esta aplicação, tais como biocompatibilidade e biodegradabilidade. Dentre os arcabouços aplicáveis à engenharia de tecido cartilaginoso o hidrogel de AH e QUI tem sido investigado e apresentam resultados promissores. O uso da blenda composta pelos hidrogéis citados é propícia à adesão, crescimento, propagação diferenciação e desenvolvimento de condrócitos, além de estimular a produção de MEC.

Estas características são de suma importância no âmbito da regeneração de tecidos e proporcionam, portanto, uma oportunidade potencial para usar hidrogéis compostos por AH e QUI em aplicações de Engenharia de Tecidos de cartilagem.

\section{Referências}

1. Olson, A., Graver, A., \& Grande, D. (2012). Scaffolds for articular cartilage repair. Journal of Long-Term Effects of Medical Implants, 22(3), 219-227. PMid:23582113. http:// dx.doi.org/10.1615/JLongTermEffMedImplants.2013006556.

2. Bittencourt, R. A. C. (2008). Cultura de condrócitos para o uso terapêutico: reconstituição de cartilagem (Tese de doutorado). Universidade Estadual de São Paulo, Botucatu.

3. Langer, R., \& Vacanti, J. P. (1993). Tissue engineering. Science, 260(5110), 920-926. PMid:8493529. http://dx.doi.org/10.1126/ science.8493529.

4. Huang, S., \& Fu, X. (2010). Naturally derived materials-based cell and drug delivery systems in skin regeneration. Journal of Controlled Release, 142(2), 149-159. PMid:19850093. http:// dx.doi.org/10.1016/j.jconrel.2009.10.018.

5. Correia, C. R., Moreira-Teixeira, L. S., Moroni, L., Reis, R. L., Blitterswijk, C. A., Karperien, M., \& Mano, J. F. (2011). Chitosan scaffolds containing hyaluronic acid for cartilage tissue engineering. Tissue Engineering, 17(7), 717-730. PMid:21517692. http://dx.doi.org/10.1089/ten.tec.2010.0467.

6. Danisovic, L., Varga, I., Zamborský, R., \& Böhmer, D. (2012). The tissue engineering of articular cartilage: cells, scaffolds and stimulating factors. Experimental Biology and Medicine, 237(1), 10-17. PMid:22156044. http://dx.doi.org/10.1258/ ebm.2011.011229.

7. Xu, X., Jha, A. K., Harrington, D. A., Farach-Carson, M. C., \& Jia, X. (2012). Hyaluronic acid-based hydrogels: from a natural polysaccharide to complex networks. Soft Matter, 8(12), 3280-3294. PMid:22419946. http://dx.doi.org/10.1039/ c2sm06463d.

8. Yan, L. P., Wang, Y. J., Ren, L., Wu, G., Caridade, S. G., Fan, J. B., Wang, L. Y., Ji, P. H., Oliveira, J. M., Oliveira, J. T., Mano, J. F., \& Reis, R. L. (2010). Genipin-cross-linked collagen/chitosan biomimetic scaffolds for articular cartilage tissue engineering applications Biomed. Materials Research, 95(2), 465-475. PMid:20648541.

9. Barbanti, S. H., Zavaglia, C., \& Duek, E. (2005). Polímeros bioreabsorvíveis na engenharia de tecidos. Polímeros: Ciência e Tecnologia, 15(1), 13-21. http://dx.doi.org/10.1590/S010414282007000400010 .

10. Multy-Agency Tissue Engineering Science-MALTES. (2013). Five Year Plan Multy-Agency Tissue Engineering Science (MALTES) Work. Recuperado em 14 de novembro de 2014, de http://www.tissueengineering.gov/tor.php 
11. Pértile, R. A. N. (2007). Estudo in vitro da interação da linhagem de fibroblastos L929com membranas de celulose bacteriana para aplicações emengenharia de tecidos (Dissertação de mestrado). Universidade Federal de Santa Catarina, Florianópolis.

12. Lombello, C. B., Reis, G. M., \& Cohen, M. (2003). Study on human chondrocyte culture viability for autologous transplantation in clinical application. Einstein, 1, 84-88. Recuperado em 14 de novembro de 2014, de http://www.einstein.br/biblioteca/ artigos/Study\%20on\%20human\%20original.pdf

13. Chapekar, M. S. (2000). Tissue engineering: challenges and opportunities. Journal of Biomedical Materials Research, 53(6), 617-620. PMid:11074418. http://dx.doi.org/10.1002/10974636(2000)53:6<617::AID-JBM1>3.0.CO;2-C.

14. Oréfice, R. L., Pereira, M. M., Mansur, S. M. (2006). Biomateriais: fundamentos e aplicações. Rio de Janeiro: Cultura Médica.

15. Chiu, L. L. Y., Chu, Z., \& Radisic, M. (2011). Comprehensive nanoscience and technology. Amsterdam: Academic Press.

16. Williams, D. F. (1987). Definitions in biomaterials: consensus Conference ESB. Amsterdam: Elsevier.

17. Lombello, C. B., Malmonge, S. M., \& Wada, M. L. (2000). PolyHEMA and polyHEMA-poly(MMA-co-AA) as substrates for culturing Vero cells. Journal of Materials Science. Materials in Medicine, 11(9), 541-546. PMid:15348383. http://dx.doi. org/10.1023/A:1008915801187.

18. Santos, A. R. Jr, \& Wada, M. L. F. (2007). Polímeros biorreabsorvíveis como substrato para cultura de células e engenharia tecidual. Polímeros: Ciência e Tecnologia, 17(4), 308-317. http://dx.doi.org/10.1590/S0104-14282007000400010.

19. Chang, C. H., Lin, F. H., Kuo, T. F., \& Liu, H. C. (2005). Cartilage tissue engineering. Biomedical Engineering Applications Basis and Communications, 17(2), 1-11. PMid:16278014. http:// dx.doi.org/10.4015/S101623720500010X.

20. Muschler, G. F., Nakamoto, C., \& Griffith, L. G. (2004). Engineering principles of clinical cell-based tissue engineering. Journal of Bone and Joint Surgery American, 86(7), 1541-1558. PMid: 15252108.

21. Hench, L. L., \& Jones, J. R. (2005). Biomaterials, artificial organs and tissue engineering. Florida: Woodhead Pub. Ltd.

22. Hollister, S. J. (2005). Porous scaffold design for tissue engineering. Nature Materials, 4(7), 518-524. PMid:16003400. http://dx.doi.org/10.1038/nmat1421.

23. Carletti, E., Motta, A., \& Migliaresi, C. (2011). Scaffolds for tissue engineering and 3D cell culture. Methods in Molecular Biology (Clifton, N.J.), 695, 17-39. PMid:21042963. http:// dx.doi.org/10.1007/978-1-60761-984-0_2.

24. Cunha, C., Panseri, S., \& Antonini, S. (2011). Emerging nanotechnology approaches in tissue engineering for peripheral nerve regeneration. Nanomedicine; Nanotechnology, Biology, and Medicine, 7(1), 50-59. PMid:20692373. http://dx.doi. org/10.1016/j.nano.2010.07.004.

25. Zhang, X., Reagan, M. R., \& Kaplan, D. L. (2009). Electrospun silk biomaterial scaffolds for regenerative medicine. Advanced Drug Delivery Reviews, 61(12), 988-1006. PMid:19643154. http://dx.doi.org/10.1016/j.addr.2009.07.005.

26. Vert, M., Doi, Y., Hellwich, K. H., Hess, M., Hodge, P., Kubisa, P., Rinaudo, M., \& Schué, F. (2012). Terminology for biorelated polymers and applications (IUPAC Recommendations 2012). Pure and Applied Chemistry, 84(2), 377-410. http://dx.doi. org/10.1351/PAC-REC-10-12-04.

27. Williams, D. F. (2008). On the mechanisms of biocompatibility. Biomaterials, 29(20), 2941-2953. PMid:18440630. http:// dx.doi.org/10.1016/j.biomaterials.2008.04.023.

28. Elias, C. N., Vasconcellos, V. S. L., \& Resende, C. R. S. (2012). Análise dos mecanismos celulares durante a osseointegração dos implantes. In Anais do VII Congresso Latino-Americano de Orgãos Artificiais e Biomateriais (pp. 1-28). São Paulo: Metallum.

29. Fortier, L. A., Barker, J. U., Strauss, E. J., Mccarrel, T. M., \& Cole, B. J. (2011). The role of growth factors in cartilage repair. Clinical Orthopaedics and Related Research, 469(10), 2706-2715. PMid:21403984. http://dx.doi.org/10.1007/s11999011-1857-3.

30. Kuo, C. K., Lia, W., Mauck, R. L., \& Tuan, R. S. (2006). Cartilage tissue engineering: its potential and uses. Current Opinion in Rheumatology, 18(1), 64-73. PMid:16344621. http://dx.doi.org/10.1097/01.bor.0000198005.88568.df.

31. Lydon, M. J., Minett, T. W., \& Tighe, B. J. (1985). Cellular interactions with synthetic polymer surfaces in culture. Biomaterials, 6(6), 396-402. PMid:4084641. http://dx.doi. org/10.1016/0142-9612(85)90100-0.

32. Dewez, J. L., Lhoest, J. B., Detrait, E., Berger, V., DupontGillain, C. C., Vincent, L. M., Schneider, Y. J., Bertrand, P., \& Rouxhet, P. G. (1998). Adhesion of mammalian cells to polymer surfaces: from physical chemistry of surfaces to selective adhesion on defined patterns. Biomaterials, 19(16), 1441-1445. PMid:9794515. http://dx.doi.org/10.1016/S01429612(98)00055-6.

33. Junqueira, L. C., \& Carneiro, J. (2013). Histologia básica. Rio de Janeiro: Guanabara.

34. Tibbitt, M. W., \& Anseth, K. S. (2009). Hydrogels as extracellular matrix mimics for 3D cell culture. Biotechnology and Bioengineering, 103(4), 655-663. PMid:19472329. http:// dx.doi.org/10.1002/bit.22361.

35. Vakonakis, I., \& Campbell, I. D. (2007). Extracellular matrix: from atomic resolution to ultrastructure. Current Opinion in Cell Biology, 19(5), 578-583. PMid:17942296. http://dx.doi. org/10.1016/j.ceb.2007.09.005.

36. Gil, L. M., Ladeira, T. C., Menezes, G. C., \& Silva, F. F. C. (2009). A interface célula-matriz extracelular-biomaterial e a biocompatibilidade de implantes de titânio. Innovation Implant Journal, 4(3), 58-64. Recuperado em 14 de novembro de 2014, de http://hdl.handle.net/10926/1894

37. Pedersen, J. A., \& Swartz, M. A. (2005). Mechanobiology in the third dimension. Biomedical Engineering, 33(11), 14691490. PMid:16341917.

38. Anselme, K. (2000). Osteoblast adhesion on biomaterials. Biomaterials, 21(7), 667-681. PMid:10711964. http://dx.doi. org/10.1016/S0142-9612(99)00242-2.

39. Clem, W. C., Chowdhury, S., Catledge, S. A., Weimer, J. J., Shaikh, F. M., Hennessy, K. M., Konovalov, V. V., Hill, M. R., Waterfeld, A., Bellis, S. L., \& Vohra, Y. K. (2008). Mesenchymal stem cell interaction with ultra-smooth nanostructured diamond for wear-resistant orthopaedic implants. Biomaterials, 29(2425), 3461-3468. PMid:18490051. http://dx.doi.org/10.1016/j. biomaterials.2008.04.045.

40. Gumbiner, B. M. (1996). Cell adhesion: the molecular basis of tissue architecture and morphogenesis. Cell, 84(3), 345-357. PMid:8608588. http://dx.doi.org/10.1016/S0092-8674(00)812799.

41. Lo, C. M., Wang, H. B., Dembo, M., \& Wang, Y. L. (2000). Cell movement is guided by the rigidity of the substrate. Biophysical Journal, 79(1), 144-152. PMid:10866943. http:// dx.doi.org/10.1016/S0006-3495(00)76279-5.

42. Pal, K., Banthia, A. K., \& Majumdar, D. K. (2009). Polymeric hydrogels: characterization and biomedical applications: a mini review. Designed Monomers and Polymers, 12(3), 197-220. http://dx.doi.org/10.1163/156855509X436030.

43. Hennink, W. E., \& Van Nostrum, C. F. (2002). Novel crosslinking methods to design hydrogels. Drug Delivery Reviews, 54(1), 13-36. PMid:11755704. http://dx.doi.org/10.1016/S0169409X(01)00240-X. 
44. Figueirêdo, E. S., Macedo, A. C., Figueirêdo, P. F. R., \& Figueirêdo, R. S. (2010). Use of hyaluronic acid in Ophthalmology. Arquivos Brasileiros de Oftalmologia, 73(1), 92-95. PMid:20464123.

45. Silva, E. M., Jr. (2012). Hidrogéis de ácido hialurônico. Santo André: Universidade Federal do ABC. Relatório de Iniciação Científica.

46. Dawson, E., Mapili, G., Erickson, K., Taqvi, S., \& Roy, K. (2008). Biomaterials for stem cell differentiation. Advanced Drug Delivery Reviews, 60(2), 215-228. PMid:17997187. http://dx.doi.org/10.1016/j.addr.2007.08.037.

47. Garg, H. G., \& Hales, C. A. (2004). Chemistry and biology of Hyaluronan. Boston: Elsevier Science.

48. Kogan, G., Soltés, L., Stern, R., \& Gemeiner, P. (2007). Hyaluronic acid: a natural biopolymer with a broad range of biomedical and industrial applications. Biotechnology Letters, 29(1), 17-25. PMid:17091377. http://dx.doi.org/10.1007/ s10529-006-9219-z.

49. Laurent, T. C., \& Fraser, J. R. E. (1992). Hyaluronan. The FASEB Journal, 6(7), 2397-2404. PMid:1563592.

50. Weigel, P. H., Hascall, V. C., \& Tammi, I. M. (1997). Hyaluronan synthases. The Journal of Biological Chemistry, 272(22), 13997-14000. PMid:9206724. http://dx.doi.org/10.1074/ jbc.272.22.13997.

51. Schramm, C., Spitzer, M. S., Henke-Fahle, S., Steinmetz, G., Januschowski, K., Heiduschka, P., Geis-Gerstorfer, J., Biedermann, T., Bartz-Schmidt, K. U., \& Szurman, P. (2012). The cross-linked biopolymer hyaluronic acid as an artificial vitreous substitute. Invest. Investigative Ophthalmology \& Visual Science, 53(2), 613-621. PMid:22199245. http://dx.doi. org/10.1167/iovs.11-7322.

52. Reitinger, S., \& Lepperdinger, G. (2013). Influence of gel properties on neocartilage formation by auricular chondrocytes photoencapsulated in hyaluronic acid networks. Gerontology, 59(1), 71-76. PMid:23006468. http://dx.doi.org/10.1159/000342200.

53. Chung, C., Mesa, J., Randolph, M. A., Yaremchuk, M., \& Burdick, J. A. (2006). Influence of gel properties on neocartilage formation by auricular chondrocytes photoencapsulated in hyaluronic acid networks. Journal of Biomedical Materials Research. Part A, 77(3), 518-525. PMid:16482551. http:// dx.doi.org/10.1002/jbm.a.30660

54. Turley, E. A., \& Naor, D. (2012). RHAMM and CD44 peptidesanalytic tools and potential drugs. Frontiers in Bioscience, 17(1), 1775-1794. PMid:22201835. http://dx.doi.org/10.2741/4018.

55. Balazs, E. A. (2004). Viscosupplementation for treatment of osteoarthritis: from initial discovery to current status and results. Surgical Technology International, 12, 278-289. PMid: 15455338.

56. Mori, M., Yamaguchi, M., Sumitomo, S., \& Takai, Y. (2004) $\mathrm{H}$ yaluran-based biomaterials in tissue engineering. Acta Histochemica et Cytochemica, 37, 1-5. http://dx.doi.org/10.1267/ ahc.37.1.

57. Raftery, R., O’Brien, F., \& Cryan, S. A. (2013). Chitosan for gene delivery and orthopedic tissue engineering applications Molecules, 18(5), 5611-5647. PMid:23676471. http://dx.doi. org/10.3390/molecules18055611.

58. Santos, J. E., Soares, J. P., Dockal, E. R., Filho, S. P. C., \& Cavalheiro, E. T. G. (2003). Caracterização de quitosanas comerciais de diferentes origens. Polímeros: Ciência e Tecnologia, 13(4), 242-249. Recuperado em 14 de novembro de 2014, de http://www.revistapolimeros.org.br/PDF/v13n4/ v13n4a06.pdf

59. Di Martino, A., Sittinger, M., \& Risbud, M. V. (2005). Chitosan: a versatile biopolymer for orthopaedic tissue-engineering. Biomaterials, 26(30), 5983-5990. PMid:15894370. http:// dx.doi.org/10.1016/j.biomaterials.2005.03.016.
60. Nwe, N., Furuike, T., \& Tamura, H. (2009). The mechanical and biological properties of chitosan scaffolds for tissue regeneration templates are significantly enhanced by chitosan from Gongronella butleri. Materials (Basel), 2(2), 374-398. http://dx.doi.org/10.3390/ma2020374.

61. Airoldi, C. (2008). A relevante potencialidade dos centros básicos nitrogenados disponíveis em polímeros inorgânicos e biopolímeros na remoção catiônica. Química Nova, 31(1), 144-153. http://dx.doi.org/10.1590/S0100-40422008000100026.

62. Cohen, M., Nery, C., Peccin, M. S., Ressio, C. R., Asaumi, I. D., \& Lombello, C. B. (2008). Autologous chondrocyte implantation to treat femoral condyle and talar lesions. Einstein, 6, 37-41. Recuperado em 14 de novembro de 2014, de http:/ www.einstein.br/revista/arquivos/PDF/693-Einstein \%20 v6n1p37-41.pdf

63. Gobbi, R. G., Demange, M. K., Barreto, R. B., Pecora, J. R., Rezende, M. U., Barros, E. P., Fo., \& Lombello, C. B. (2010). Transplante autólogo de condrócito: relato de três casos. Revista Brasileira de Ortopedia, 45(4), 449-456. PMid:27022579. http://dx.doi.org/10.1590/S0102-36162010000400019.

64. Nery, C., Lombello, C. B., Ressio, C. R., \& Asaumi, I. D. (2010). Implante autólogo de condrócitos no tratamento das lesões osteocondrais do talo. Revista ABTPé, 4, 113-123. Recuperado em 14 de novembro de 2014, de http://www. researchgate.net/publication/236343035_Revista_da_ABTP

65. Moroz, A., Bittencourt, R. A. C., Felisbino, S. L., Pereira, H. R., Ferreira, R., \& Deffune, E. (2008). Gel de plaquetas: arcabouço 3D para cultura celular. Acta Ortopedica Brasileira, 17(2), 43-45. http://dx.doi.org/10.1590/S1413-78522009000200008.

66. Laranjeira, M. C. M., \& Fávere, V. T. (2009). Quitosana: biopolímero funcional com potencial industrial biomédico. Quimica Nova, 32(3), 672-678. http://dx.doi.org/10.1590/ S0100-40422009000300011.

67. Kaderli, S., Boulocher, C., Pillet, E., Watrelot-Virieux, D., Rougemont, A. L., Roger, T., Viguier, E., Gurny, R., Scapozza, L., \& Jordan, O. (2015). A novel biocompatible hyaluronic acid-chitosan hybrid hydrogel for osteoarthrosis therapy. International Journal of Pharmaceutics, 483(1-2), 158-168. PMid:25666331. http://dx.doi.org/10.1016/j.ijpharm.2015.01.052.

68. Ma, G., Liu, Y., Fang, D., Chen, J., Peng, C., Fei, X., \& Nie, J. (2012). Hyaluronic acid/chitosan polyelectrolyte complex nanofibers prepared by electrospinning. Materials Letters, 74 , 78-80. http://dx.doi.org/10.1016/j.matlet.2012.01.012.

69. Tan, H., Chu, C. R., Payne, K., \& Marra, K. G. (2009). Injectable in situ forming biodegradable chitosan-hyaluronic acid based hydrogels for cartilage tissue engineering. Biomaterials, 30(13), 2499-2506. PMid:19167750. http://dx.doi.org/10.1016/j. biomaterials.2008.12.080.

70. Sung, H. W., Huang, R. N., Huang, L. L. H., Tsai, C. C., \& Chiu, C. T. (1998). Feasibility study of a natural cross-linking reagent for biological tissue fixation. Journal of Biomedical Materials Research, 42(4), 560-567. PMid:9827680. http:// dx.doi.org/10.1002/(SICI)1097-4636(19981215)42:4<560::AIDJBM12>3.0.CO;2-I.

71. Ferretti, M., Marra, K. G., Kobayashi, K., Defail, A. J., \& Chu, C. R. (2006). Controlled in vivo degradation of genipin crosslinked polyethylene glycol hydrogels within osteochondral defects. Tissue Engineering, 12(9), 2657-2663. PMid:16995799. http://dx.doi.org/10.1089/ten.2006.12.2657.

72. Collins, M. N., \& Birkinshaw, C. (2013). Hyaluronic acid based scaffolds for tissue engineering: a review. Carbohydrate Polymers, 92(2), 1262-1279. PMid:23399155. http://dx.doi. org/10.1016/j.carbpol.2012.10.028.

73. Muzzarelli, R. A. A., Greco, F., Busilacchi, A., Sollazzo, V., \& Gigante, A. (2012). Chitosan, hyaluronan and chondroitin sulfate in tissue engineering for cartilage regeneration: a review. 
Carbohydrate Polymers, 89(3), 723-739. PMid:24750856. http://dx.doi.org/10.1016/j.carbpol.2012.04.057.

74. Yamane, S., Iwasaki, N., Majima, T., Funakoshi, T., Masuko, T., Harada, K., Minami, A., Monde, K., \& Nishimura, S. (2005). Feasibility of chitosan-based hyaluronic acid hybrid biomaterial for a novel scaffold in cartilage tissue engineering. Biomaterials, 26(6), 611-619. PMid:15282139. http://dx.doi. org/10.1016/j.biomaterials.2004.03.013.

75. Walker, K. J., \& Madihally, S. V. (2015). Anisotropic temperature sensitive chitosan-based injectable hydrogels mimicking cartilage matrix. Journal of Biomedical Materials
Research. Part B, Applied Biomaterials, 103(6), 1149-1160. PMid:25285432. http://dx.doi.org/10.1002/jbm.b.33293.

76. Lu, H., Lv, L., Dai, Y., Wu, G., Zhao, H., \& Zhang, F. (2013). Porous chitosan scaffolds with embedded hyaluronic acid/ chitosan/plasmid-DNA nanoparticles encoding TGF- $\beta 1$ induce DNA controlled release, transfected chondrocytes, and promoted cell proliferation. PLoS One, 8(7), 1-42. PMid:23894564. http://dx.doi.org/10.1371/journal.pone.0069950.

Enviado: Nov. 14, 2014 Revisado: Ago. 14, 2015 Aceito: Dez. 16, 2015 